\title{
IRON CONTAMINATION DURING COMMERCIAL GRINDING OF SPICES
}

\author{
JANITHA P. PANDUWAWALA, CHAMARA D.K. ILLEPERUMA AND
}

U. SAMARAJEEWA

Department of Food Science \& Technology, University of Peradeniya, Peradeniya, Sri Lanka.

(Date of receipt : 29 May 1987)

(Date of acceptance : 06 January 1988)

\begin{abstract}
The concentration of copper, iron and zinc were estimated by atomic absorption spectrophotometry in powdered spices purchased from retailers. The three elements were compared by grinding the whole spices by mortar and pestle, grinding stone, food blender and in commercial mills. The iron, due to wear and tear of the machinery, contaminate the spices during commercial grinding increasing the iron content $3-5$ fold; the concentrations being as high as $750 \mu \mathrm{g} / \mathrm{g}$ of ground spices. Highest contamination were seen in turmeric powder. The iron contaminated spices are ferromagnetic confirming the particulate nature of iron in spices. The copper and zinc content were comparable in the replicates ground by different methods as well as in the samples purchased from retailers. Further study on the nutritional significance of iron contamination in ground spices appears warranted.
\end{abstract}

\section{Introduction}

Spices are added to enhance the flavour, aroma and colour of food but are not considered as sources of minerals or other nutrients. Ground spices are reported to contain high iron concentrations, sometimes 3--4 times higher than in other edible plant components, implicating possible nutritional benefits through the spices. ${ }^{3,6}$ However, the origin of such high levels of iron is not understood.

In this study, experiments were directed at determining the origin of the copper, iron and zinc content of ground spices.

\section{Materials and Methoids}

\subsection{Spices}

The following whole or commercially ground spices and curry powder were purchased from the retailers in Gampaha, Kandy, Matale, Nugegoda, Peradeniya and Warakapola. 
Pods of ripe chillie (Capsicum annuum)

Berries of pepper (Piper nigrum)

Rhizomes of turmeric (Curcuma longa)

Seeds of coriander (Coriandrum sativum)

Fruits of cumin (Cuminum cyminum)

\subsection{Grinding}

Whole spices were washed with demineralized water, and dried at $70^{\circ} \mathrm{C}$ in the vacuum oven. Replicate samples of the dried spices were ground by the following methods:

(a) In a laboratory mortar and pestle

(b) In a clean grinding stone at kitchen

(c) In a food blender (National Model MX-11PN)

(d) In commercial mills in Kandy method.

Estimations were made from triplicate samples ground by each

\subsection{Estimation of copper, iron and zinc}

The powdered spices $(1 \mathrm{~g})$ were ignited in a muffle furnace at $460^{\circ} \mathrm{C}$ for eight hours. This was moistened with glass distilled demineralized water $(2 \mathrm{ml})$ and concentrated nitric acid $(5 \mathrm{ml})$ and warmed for few minutes over the flame. The solutions were filtered in to $100 \mathrm{ml}$ volumetric flasks through Whatman No. 541 filter paper and made up to the mark.

The estimations were carried out using a Perkin-Elmer Model 2380 Atomic Absorption Spectrophotometer containing an adjustable titanium burner head and air/acetylene flame, using high intensity "Intensitron" lamps at the wave lengths and slit widths given in Table $1 .^{7}$

Table 1

\begin{tabular}{lll}
\hline element & wave length $(\mathrm{nm})$ & slit $(\mathrm{nm})$ \\
\hline copper & 324.8 & 0.7 \\
iron & 248.3 & 0.2 \\
zinc & 213.9 & 0.7 \\
\hline
\end{tabular}

The quantitative analysis of the elements were conducted using standard curves obtained using the same instrument, for standard solutions containing the respective cations. ${ }^{2}$ The coefficient of variation for the determinations varied up to $15 \%$ for the home ground samples and up to $40 \%$ for 
the mill ground samples; the values for commercially purchased samples varied between $15-79 \%$.

\subsection{Ferromagnetism}

The powdered spices were firmly packed to a length of $4 \mathrm{~cm}$ in a glass tube of $10 \mathrm{~cm} \times 10 \mathrm{~mm}$ (internal diameter) and suspended in a double pan laboratory balance at the centre of an electromagnet set underneath the balance. The tube was balanced using the weights.

A magnetic field strength of up to 3000 oersted was produced by the electromagnet with pole gap of $2 \mathrm{~cm}$, resistance of $15.3 \mathrm{ohm}$ and 2337 turns which was supplied with a power of 22 volts and $4.5 \mathrm{amp}$ to produce a magnetic flux of 60 maxwell turns using Eleminac type B 2027 generator. The magnetic flux produced was measured by a calibrated fluxmeter in maxwell turns per $100 \mathrm{~cm}^{2}$ search coil. ${ }^{5}$

\section{Results and Discussion}

\subsection{Commercially ground spices}

The powdered spices purchased from the retailers contained high iron content as already reported ${ }^{6}$ and the copper and zinc contents were much less than iron (Table 2). The iron content varied widely among the samples with standard deviations up to $70 \%$ of the mean whereas the standard deviations for copper and zinc contents were less than $30 \%$ of the mean. The high inhomogeneity of iron content in commercial spice powders suggest the presence of iron as a contaminant rather than a naturally occurring constituent of the raw materials.

The iron content in the commercial powders did not show any correlation with the location of purchase. Of the different types of spices examined turmeric had the highest iron content (Table 2).

\subsection{Home ground spices}

The spices ground by three methods at home/laboratory showed comparable figures for copper, iron and zinc content (Table 3). The iron content found in the home ground spices was only 25 to 35 per cent of the levels reported in commercially ground spices. In contrast to the iron content, the copper and zinc contents were the same in both home ground and commercially purchased spices further indicating the high iron content to be a contamination during grinding in commercial mills. 
Table 2. Copper, iron and zinc concentrations $(\mu \mathrm{g} / \mathrm{g})$ in commercial powdered spices purchased from retailers.

\begin{tabular}{|c|c|c|c|c|c|}
\hline Spice & element & No. of samples & Mean & S.D. & Range \\
\hline Chillie & & $\therefore$ & & & \\
\hline & copper & & 36.3 & 14.4 & $22-64$ \\
\hline & iron & & 458.0 & 144.2 & $214-80$ \\
\hline & zinc & & 20.0 & 7.3 & $10-30$ \\
\hline
\end{tabular}

Curry

copper

iron

zinc

Pepper

copper

iron

zinc
33.1

608.1

29.0

5

Turmeric

copper

iron

zinc
15

$\begin{array}{crc}52.8 & 11.8 & 38-71 \\ 449.4 & 326.0 & 100-912 \\ 19.4 & 8.4 & 8-28\end{array}$

$\begin{array}{rc}5.8 & 22-41 \\ 396.1 & 197-1998 \\ 4.4 & 24-40\end{array}$


Table 3. Copper, iron and zinc concentrations $(\mu \mathrm{g} / \mathrm{g})$ in spices ground using mortar anc pestle, grinding stone or food blender.

\begin{tabular}{llll} 
Spice & & Method of grinding \\
\hline element & $\begin{array}{l}\text { mortar \& } \\
\text { pestel }\end{array}$ & $\begin{array}{l}\text { grinding } \\
\text { stone }\end{array}$ & $\begin{array}{l}\text { food } \\
\text { blender }\end{array}$
\end{tabular} Mean \pm S.D.

Chillie (3)

$\begin{array}{lrrrr}\text { copper } & 49 & 43 & 41 & 44.3 \pm 3.3 \\ \text { iron } & 126 & 138 & 133 & 132.3 \pm 4.9 \\ \text { zinc } & 18 & 16 & 12 & 15.3 \pm 2.4\end{array}$

Coriander (3)

$\begin{array}{lrrrr}\text { copper } & 41 & 38 & 35 & 38.3 \pm 2.4 \\ \text { iron } & 143 & 146 & 147 & 145.3 \pm 1.6 \\ \text { zinc } & 32 & 30 & 28 & 30.0 \pm 1.6\end{array}$

Cumin (3)

$\begin{array}{lrrrr}\text { copper } & 49 & 49 & 44 & 47.3 \pm 2.3 \\ \text { iron } & 170 & 178 & 167 & 171.6 \pm 4.6 \\ \text { zinc } & 30 & 28 & 25 & 27.6 \pm 2.0\end{array}$

Pepper (3)

$\begin{array}{lllll}\text { copper } & 54 & 52 & 54 & 53.3 \pm 0.9 \\ \text { iron } & 74 & 70 & 68 & 70.6 \pm 2.4 \\ \text { zinc } & 24 & 25 & 28 & 25.6 \pm 1.6\end{array}$

Turmeric (3)

\begin{tabular}{lrrrr} 
copper & 30 & 25 & 24 & $26.3 \pm 2.6$ \\
iron & 130 & 143 & 140 & $137.6 \pm 5.5$ \\
zinc & 28 & 28 & 29 & $28.3 \pm 0.4$ \\
\hline
\end{tabular}

Results for the same samples ground in the mill. 
Among the spices cumin seed is reported to be a naturally rich source of iron ${ }^{4}$ containing $950 \mu \mathrm{g} / \mathrm{g}$. The samples examined in this study contained only $170 \mu \mathrm{g} / \mathrm{g}$ of iron in cumin seeds.

\subsection{Commercial grinders}

When replicates from the whole spices ground at home were ground in commercial grinders, a 3-5 fold increase in the iron content was noted whereas the copper and zinc contents were the same as in home ground spices (Figure 1) confirming that iron contamination occurs during grinding. The added iron content varied from mill to mill widely. Of the 10 grinding mills compared for added iron content (Table 4) the mill No. 1 exhibited highest contamination for all types of spices.

The grinders used in Sri Lanka are of "burr type" and consist of two roughened cast iron discs, where flutes are grooved in the two facing sides. One plate rotates on a shaft and the whole spices are fed between the plates for grinding by crushing and shearing action. It is quite possible that iron, in a fine particulate form, is produced due to wear and tear during grinding. The higher iron content noted with turmeric (Table 2 and 4) is probably due to higher hardness of turmeric rhizomes causing greater wear and tear compared with the other spices. It is also possible that higher iron contamination occur.in grinding mills where the plates are new and rough.

\subsection{Magnetic properties}

If iron contamination occurs in spices during grinding, the particulate nature of iron should add a ferromagnetic effect to the ground spices when tested by Gouy method. ${ }^{5}$ Home ground spices when subjected to a magnetic field were diamagnetic, exerting no force whereas the commercially ground spices exhibited a positive force on the balance confirming the particulate nature of iron. However, the ferromagnetic force was not sufficiently strong to be measured under our experimental conditions.

\subsection{Nutritional significance}

In cooking foods the total amount of spices added average to $5-10 \mathrm{~g}$ per person with a possible daily contribution of $5 \mathrm{mg}$ iron per person from spices containing about $500 \mu \mathrm{g} / \mathrm{g}$ of iron, as observed in this study. This falls very close to the recommended daily dietary allowance of $6-15 \mathrm{mg}$ or iron. ${ }^{8}$ However, iron existing in the ferric state in the powdered spices may not be readily available for absorption during digestion. ${ }^{10}$ The bioavailability of iron depends on several parameters. On one hand the presence of ascorbic acid and citric acid contributed from lime during cooking of vegetables may convert the iron into chelate forms that could be readily absorbed. On the 

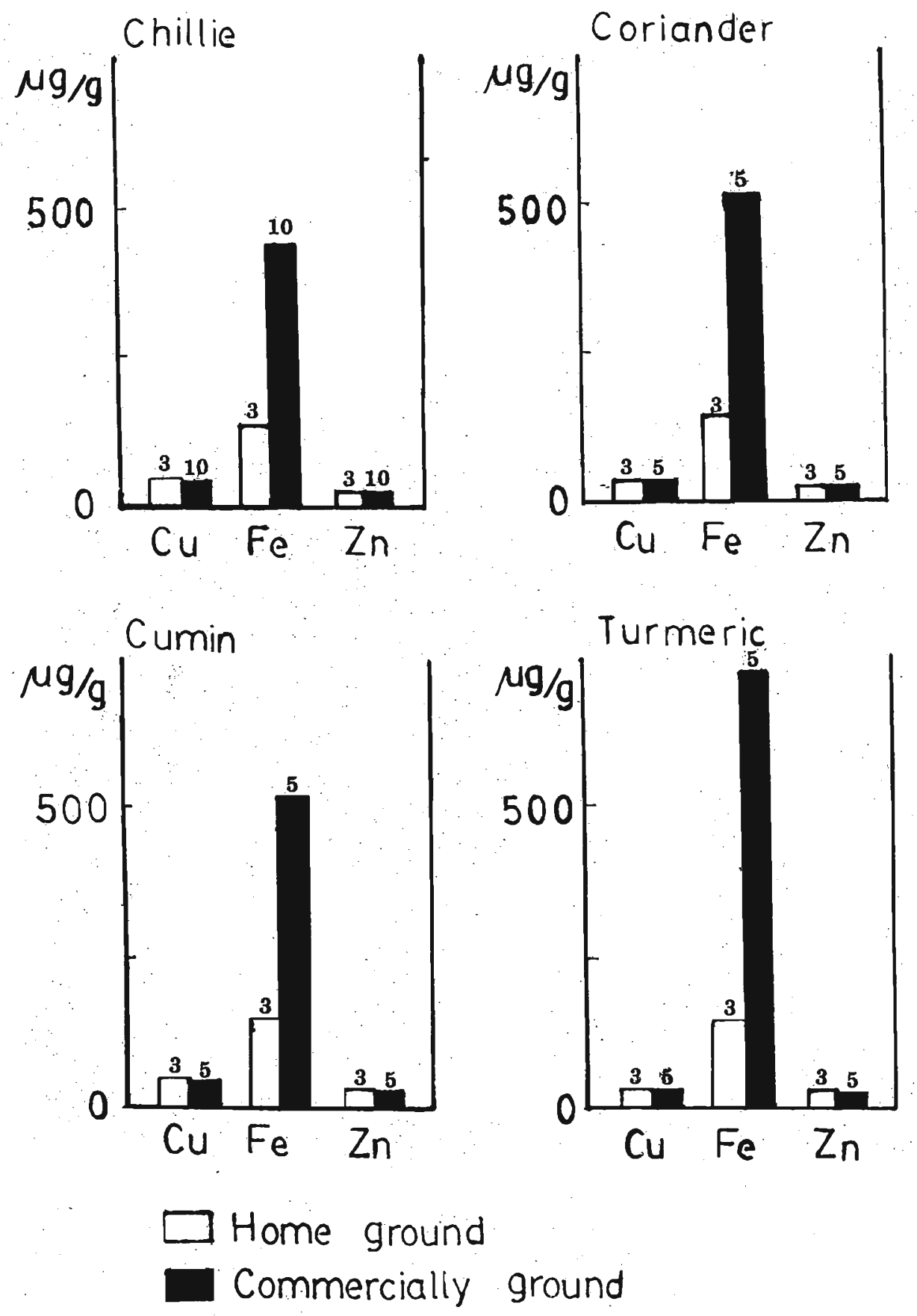

Figure 1. Copper, iron and zinc concentrations $(\mu \mathrm{g} / \mathrm{g})$ in spices ground at home and commercial mills from the same samples of whole spices. Figures on bars refer to the number of samples assayed. 


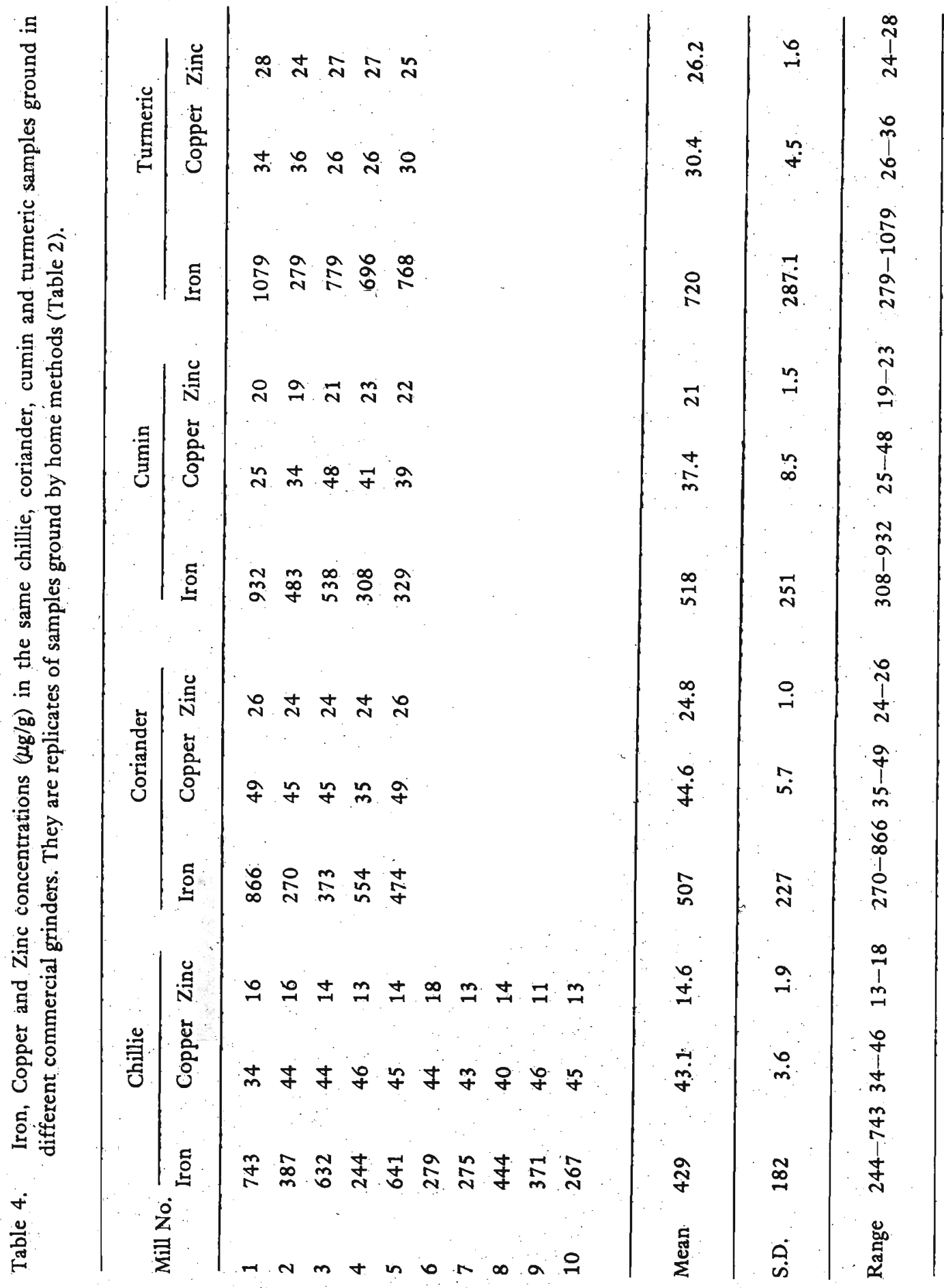


other hand the iron may be complexed by phytates or oxalates or made insoluble by phosphates making them non-available for absorption. Consumption of contaminated foods that provide $100 \mathrm{mg}$ iron per day is reported to cause siderosis in the Bantu populations. ${ }^{10}$ The spices cannot contribute such high iron levels to foods.

Iron in the ferric state may also produce negative effects on foods by oxidizing the anthocyanin pigments, which contribute colour to the foods and oxidizing ascorbic acid and other antioxidants in foods. The possible implications of the iron contamination from grinding mills on the nutrition need be examined further as spices are consumed considerably by Sri Lankans.

Zinc at concentrations above $40 \mathrm{mg} / \mathrm{kg}$ in water is reported to cause adverse physiological reactions in humans. 9 The maximum acceptable daily intake of copper is $0.5 \mathrm{mg} / \mathrm{kg}$. ${ }^{9}$ The contribution of zinc and copper to foods by the spices is much lower and could not be hazardous.

\section{Conclusions}

Contamination of iron due to wear and tear of the parts of mills cause $3-5$ fold increase in iron content, in commercially ground spices. The iron appears in the particulate form in the spice powders. Further study on the nutritional significance of iron contamination in ground spices appears warranted.

\section{Acknowledgements}

We wish to thank Dr. M.A. Careem of Department of Physics, University of Peradeniya, for providing the facilities for magnetic measurements and Mrs. C. Baranage of the Food Testing Laboratory, Municipal Council, Kandy for providing commercially ground spices.

\section{REFERENCES}

1. ANONYMOUS (1970). Fourteenth report of the joint FAO/WHO Expert Committee on Food Additives. Geneva 36 p.

2. CHAPMAN, H.H. \& PRATT, P.F. (1961) Metbods of analysis of soils, plants and water. University of California, Division of Agricultural Sciences. p. 161-175.

3. CHRISTENSEN, R.E., BECKMAN, R.M. \& BIRDSALL, J.J. (1968) J. Assoc. Offic. Anal. Chem., 51: 1003 . 
4. FOX, SUSAN, J. \& BENDER, A.E. (1977) J: Food Tecbnol., 12: 535-539.

5. LEWIS, J. \& WILKINS, R.G. (1960) Modern Co-ordination Chemistry p. 400, Wiley Interscience Publishers, New York.

6. PAUL, A.A. \& SOUTHGATE, D.A.T. (1978) The Composition of Foods, Fourth revised and extended edition of M.R.C. Special Report No. 297: 271: Elsevier North-Holland Biomedical Press, Amsterdam.

7. PERKIN-ELMER (1976) Analytical Metbods for Atomic Absorption Spectrophotometry, Norwalk, Connecticut, USA. p.1-12.

8. PYKE, M. (1982) Success in Nutrition, John Murray (Publishers) Ltd., London. $115-121$.

9. STUTTS, V.J. (1981) Nutritional hazards, In Food Safety, edited by Robert, H.R. John Wiley \& Sons, 113 p. New York, p. 113.

10. UNDERWOOD, E.J. (1977) Trace Elements in Human and Animal Nutrition, 25 p, Fourth Edition, Academic Press, London. 